\title{
Understanding Agency in Interaction Design Materials
}

\author{
Jakob Tholander \\ Mobile Life@ Stockholm \\ University \\ P.O. Box 1197 \\ SE-164 26 Kista, Sweden \\ jakobth@dsv.su.se
}

\author{
Maria Normark \\ Mobile Life and \\ School of Communication, \\ Media and IT \\ Södertörn University \\ SE-141 89 Huddinge, Sweden \\ maria.normark@sh.se
}

\author{
Chiara Rossitto \\ Dept. of Computer and \\ System Sciences (DSV) \\ Stockholm University \\ Forum 100 \\ SE-164 40 Kista, Sweden \\ chiara@dsv.su.se
}

\begin{abstract}
We draw on the concept of agency in order to understand the process of how design materials 'talk back' to designers. In so doing, we illustrate the various levels at which agency can emerge in the context of intensive shorttime prototyping sessions. In HCI, it is often assumed that the designer is the agent that acts intentionally in the design process. Contrary to this, recent notions of agency provide a way of analysing the performative role of design materials as intra-actions between components within a given phenomenon, rather than as meanings merely ascribed by actions of designers. The notion of agency puts focus on the emerging properties of materials and how they actively contribute to the way that design activity unfolds. The analyses showed how interaction design is to a large extent driven by emergent characteristics of available materials. The results have implications for understanding material interactions and materiality in interaction design.
\end{abstract}

\section{Author Keywords}

Agency; Materiality; Material Interactions; Interaction Design

\section{ACM Classification Keywords}

H.5.m [Information Interfaces and Presentation]: Miscellaneous;

\section{INTRODUCTION}

Schön's idea that design materials 'talk back' to designers' is broadly acknowledged within the HCI community [24]. He showed how competent designers are able to read qualities in a design object, and use such qualities to further elaborate a specific design idea. This line of thinking has been central to research focused on understanding the competencies of designers, thereby stepping away from some of the often 'dualistic' [19] or 'mysterious' [4] views of what design thinking actually is. Nevertheless, HCI as a field still needs further insights into understanding how this 'talking back' occurs in practice, in other words, what

Permission to make digital or hard copies of all or part of this work for personal or classroom use is granted without fee provided that copies are not made or distributed for profit or commercial advantage and that copi bear this notice and the full citation on the first page. To copy otherwise, or republish, to post on servers or to redistribute to lists, requires prior specific permission and/or a fee.

CHI'12, May 5-10, 2012, Austin, Texas, USA.

Copyright 2012 ACM 978-1-4503-1015-4/12/05...\$10.00. exactly do materials say to designers throughout concrete interaction design processes? We draw on the concept of agency in order to provide an answer to this question. In so doing, we illustrate the various levels at which agency emerge in the context of intensive short-time prototyping sessions. We argue that a more nuanced understanding of agency provides a way to talk about how creativity emerges in the situated interactions between designers and their materials. In other words, agency may expand our understanding of how materials 'talk back' and become active agents in interaction design processes. Furthermore, we argue that this will provide richer ways of perceiving the plethora of novel digital and interactive materials that we currently see in HCI. More generally, we also hope to contribute to an expanded view on people-technology relationships, the different forms those relationships may take, and thereby, promote approaches to interaction design in which the materials we work with are viewed in alternative ways.

Agency is a concept that has a long history in the area of interaction with, and design of, intelligent interfaces (IUI), robotics, game avatars, and conversational agents. While, agency has primarily been discussed in relation to systems displaying degrees of intelligence, intentionality, or autonomous and rational behaviour, there is less work that has viewed agency as a way of understanding the role of more mundane materials, such as pen, paper, clay, post-its, Lego, etc., commonly used in initial stage of interaction design activities.

Ascribing agency to non-human subjects often relates to discussions concerned with intentional and purposeful behaviour, and whether it can be regarded as similar to human intentions. This frequently ends up in an either-or view on the nature of agency. Latour describes this as a dichotomy between human-centred versus object-centred notions of agency: "Either objects do nothing, except deceive, or they do too much. Either they are totally manipulated by humans; or it is them, on the contrary, which manipulate unsuspecting humans. Either they are caused or they cause." (p. 236, [14]). In order to overcome this dichotomy Latour suggests that all material objects are possible actants and, as such, with a potential capacity for agency. To illustrate this point, Latour provides the 
example of a shepherd, his sheep, and a fence. His argument is that an object like a fence, generally perceived as static, or 'dead', can act without having to display any intentionality. However, within the activity of shepherding, the fence is an actor in keeping the sheep inside the grounds, and it actively performs this task even when the shepherd is asleep. Artefacts can therefore act without having to simulate any kind of intentional or intelligent behaviour.

The dichotomy addressed above is also reflected in HCI's concern with design of artefacts that actively play a role in human activities, and especially with recent attempts at conceptualising the role of materials in interaction design $[22,23,30]$. In this paper we seek to further develop this understanding, by illustrating how agency as a notion can provide a richer understanding of how materials 'talk back' to designers, in specific moments of interaction design processes. It should be noted that the goal of this work is not to contribute to theorizing agency as such, but to provide situated examples of how it practically plays out in interaction design, and how that helps us draw out critical aspects for understanding interaction design practice.

The empirical material comes from a series of field experiments conducted to shed light on how first-year university students in interaction design approach a given design exercise, and how they give shape to their ideas in sketches and lo-fi prototypes. In particular, we sought to understand how the state of the design ideas and its different material manifestations contributed to the final outcome of the design process. We decided to analyse the data, by taking the material as the unit of analysis. The choice to look at first-year students was motivated by our interest in understanding how interaction designers use and explore the design materials they are provided with. We thought that the lack of a consolidated previous experience regarding the use of a specific material would enable us to better understand how agency unfolds as people appropriate such materials.

\section{MATERIALITY IN DESIGN AND INTERACTION}

The nature of interaction design practice and research has been increasingly discussed at recent $\mathrm{CHI}$ conferences. A number of papers have contributed to a deeper understanding of interaction design. Among others, these include Fällman's distinction between design as research and research as design [7], Wolf et al's discussion of the need to not treat design as a 'black art' [33], Zimmerman' notion of 'research through design' [34], as well as the emerging area of interaction design critique (see eg. [2]). In light of these discussions regarding the nature of interaction design and interaction design research, our work aims at further contributing to this area of work by putting specific focus on how to understand the material aspects of interaction design.

The interactive role of design materials has been acknowledged in interaction design at least since Schön's seminal work on reflective practices in architecture studios, and the idea that for a competent designer the material 'talks back' in a dialogue with the designer [24]. Similarly, Löwgren and Stolterman discuss how artists often constrain their creative processes by choosing specific materials and techniques [16]. In a similar vein, a number of papers [23], [27], [30] and [31] have argued for the need for a deeper reflection on how to understand the role of materials in design, in what has been coined a "material turn" [22]. This line of argumentation addresses the need to give digital materials a more prominent role in understanding interaction design, and to create a richer language for talking about the active role that materials play [24].

That physical and virtual objects shapes social interaction has been a critical theme of much work coming out of ethnographic and interaction analysis perspectives in $\mathrm{HCI}$ and CSCW. These have brought forth notions of how embodied interaction plays out in creative work [e.g. 18, 19]. Many studies along these lines have shown the various ways people use physical and digital artefacts as mediating instruments in social and collaborative interaction. Others have more specifically been oriented towards understanding interaction design through the notion of performance, suggesting a view from which humans - as well as objects actively perform in design processes 11, 12]. Similarly, Binder et al's [3] recent book on design things indicates a focus on the role of objects in design process, rather than on processes of design thinking.

In HCI, it has often been assumed that the designer is the sole agent that acts intentionally in design activities. In our case, when analysing student projects, it became visible that the design is also to a large extent driven by characteristics of available materials. Recent theories on agency provide a way of analysing the performative role of design materials, as 'intra-actions' between components within a given phenomenon, rather than as meanings ascribed by the singular actions of the designers [1, 21, 26]. In pursuing this, we start out from the perspective initiated by Suchman [25], proposing how agency is not an attribute of either humans or non-humans, but rather effects of outcomes, generated though specific configurations of human and non-human entities. The notion of configuration in this context suggests that each component, either human or nonhuman always participates and becomes meaningful within a constantly reconfigured phenomenon.

Suchman's work on human and machine agency, and her critique of the ambitions of designing intelligent machines [25] argued that the primary reason for the difficulty of making interactive machines that display human-like intelligence is due to the asymmetry in access to interactional resources between humans and machine's. The richness in the resources that humans have access to and draw upon - in comparison to computers - is the primary reason for break-downs in the interaction. In her later work, she has refined and clarified her position. Rather than claiming that there would be a distinct difference, or 
boundary, that could be drawn between humans and machines, she argues that intelligible interaction is created through a constantly on-going negotiation creating a shifting boundary unfolding through practice. The nature of such boundaries has been explored in some of Taylor's recent work on the practical circumstances under which we see machines as displaying intelligent or autonomous behaviour [28]. A related standpoint is developed in Hayles' [9] work on the materiality of the digital that suggests how information technology cannot be understood as isolated from its material manifestations and their relation to human action. Her notion connects to distributed cognition by suggesting that bodies never act with complete agency nor do they act completely without agency. This rethinking of autonomous and intelligible behaviour of interactive artefacts together with recent work on the role of materiality in interaction design, suggests a need to further explore processes of interaction design in which the digital and physical materials are looked up as from the point of view of agency. Our approach connects to Hayles' view on agency and materiality and seeks to approach it as temporarily and continuously emerging in a particular situation.

Notions of agency is not new to HCI, in particular it became a central aspect in the critique of the information processing paradigm that dominated much of HCI and cognitive science of 80 s and early 90 s. One line of critique focused on how cognitive processes are distributed, or in Lave's terms [15], stretched over, not divided among, mind, bodies, activities, and artefacts. One key issue of this work regards the locus of cognition - is it happening only in the human mind, or in a larger system of interacting components? However, our reading of these views on agency in relation to distributed cognition [10] is that they primarily look at systems of information processing and thereby implicitly downgrade important interactional qualities.

The idea of agency in objects has similarities to the widely used concept of affordance. The concept of affordance [8], [20] suggests that humans interpret possible usage of an object from its shape and their earlier experience. The important difference is that affordances of objects can be discovered by users, while agency emerges in a continuous on-going dialogue between humans and things in a specific context. Clay, for example, affords moulding, cutting, stretching and so on. However, the notion of affordances does not provide ways of understanding how a particular action interactively shapes the on-going process. Recent notions of agency focuses on exactly this; i.e. how interactional possibilities of materials unfold in interaction with users and other actors. Agency is thus not to be viewed as a fixed property embedded in the object, but enacted in the relationships between people and artefacts. We argue that drawing on the notion of agency provides a ground to better understand how materials talk back to designers, and hence, the role materials play in design processes. By assuming that neither technology nor people are the sole performing agents that drive an activity forward - but rather the two in interplay - it is possible to scrutinize the way that design materials actually contribute to shaping the design process.

\section{METHOD AND SETTING}

The case presented shows particular aspects of the design processes, namely brainstorming and lo-fi prototyping. The data concerning the use of design materials in the context of these activities where collected by means of field experiments with first-year interaction design students. A total of eight groups volunteered to participate in the field experiment, each group consisting of 4 up to 5 students. All the participants were attending a course in Interaction Design which, at the time of the study, was the students' first course within their bachelor program. The field experiment was carried out at two different locales within our university: an Interaction Design lab, and a centre for digital art. The groups were equally distributed so that four groups were present at each of these sites.

The field experiment was organized into two main parts. During the first one, each group was asked to work on one of the two design briefs that were handed out. During the second one, each group was requested to present its design idea to another group through the enactment of a scenario. One of the design briefs focused on physical twittering, and the task was to elaborate design concepts addressing the possibility of physical and body interactions. The participants were also asked to explicitly address issues regarding the context of use of the technology, or temporal aspects of people's interactions with it. The other brief was concerned with envisioning technologies for elderly homes; issues of simplicity and integration into everyday life were central to this second brief. Before the task began, all the participants were given a document with one of the briefs. They were also informed about the time constraints on their assignment: namely ten minutes to read and discuss the brief within the group, and twenty minutes to actually prototype the design idea. Furthermore, the students were allocated 30 minutes to present their idea to the other group acting as opponent. One of the researchers kept track of time and reminded the participants of the time left. All the groups were provided with various resources (play-doh, Lego, paper, plastic paper, paper, scissors, pencils etc.) they could use throughout their design session. The two rooms were also equipped with whiteboards the students could use as they wished.

All the group sessions were video-recorded, for a total of about eight hours of video. Two video cameras were used at each site where the study was carried out; pictures were also taken by one of the researchers. In this first phase of analysis we have made a qualitative analysis of the video data with the specific purpose of looking at how agency manifests itself. The data has been analysed by adopting an interactional analysis approach [17]. 
In the following analysis we have chosen excerpts from a group working on the physical twittering assignment. Insofar, we have limited our analysis to the timeframe when the participants actually developed their design concept, and not when it is presented to the opponent group. Our reason for discussing only one group from the field experiment was that we wanted to provide as much of a complete and in-depth narrative of a design process. While the eight groups solved the design problem in different ways, we find that our argument is best developed by presenting one in detail. The excerpts span over a period of thirty minutes and they were chosen since they illustrate different instances of how agency emerges in the interactions between the people involved, the material used, and the design brief at hand. It should be noted that this moments do not embody final states in the development of the design ideas. Each one of them is a temporary outcome that contributes to a further transformation of the design ideas being discussed.

\section{MATERIALITY IN INTERACTION DESIGN}

The design session presented goes through two distinct phases. The first one can be characterized as an ideation and conceptualization phase, while the second involves establishing how interactions and expressions will be manifested through a prototype. We would like to emphasize the transformations that the design goes through in these two phases, and in particular, the role played by the material resources in shaping the design. We start out by characterizing the two phases and the main actions that the users engage in throughout these. Next, we will look more detailed into four excerpts.

The two students, Anna and Anton, start out by quietly reading the design brief. Anna suggests that they could design "a little friend" that you bring a long, "like a bird". This proposal evolves into a discussion that their prototype could be like a Tamagotchi that you bring with you. They talk about how the bird could be connected to your Twitter account and be used both to formulate expressions through, by performing "little dances or wing flaps", as well as for expressing messages to its owner.

The idea of a physical bird quite immediately directs them into talk about how interaction could be played out through the bird. Starting out from this initial discussion they repeatedly turn to the design brief and they continuously jot down notes on the ideas they come up with in this process. After the initial discussion that establishes that they will focus on designing a physical twitter-bird (even though they do not explicitly state this decision) Anna starts sketching the bird on the back of the design brief. This leads them to start considering more detailed aspects of the interaction by specifically thinking though the possibilities for interaction that is given by the idea of a physical bird, and especially bodily and physical forms of interaction. For instance, they talk about "performing dances", and how it more easily "might be able to do things like this, stomp, to ask for attention", or "to flap the wings if there is a party". These ideas were accompanied by expressive bodily movements intended to illustrate forms of input to, or expressions by the bird.

In the second phase of the design session, they move over to another table in the room where they have different design and play materials available, such as clay, coloured pens, coloured papers, and Lego. They decide to make a prototype in clay and to make it purple. This develops into a process where the making of the prototype is accompanied by talk and considerations regarding different interactional properties of the prototype. They form questions such as "what one does to formulate a message to other people", or "how you decide who a message should be sent to". What we would like to bring up in this phase is how the properties of a bird, such as having wings that can be flapped, or a beak that could be pecked with, brings about certain ideas for interaction. One idea that came up was that one should be able to lift the wings to control settings of the prototype and that one could direct messages to certain people by flapping the wings. Instead of expressing ideas for interaction by pretending to be a bird like they did in the first phase, they now express them by performing them through manipulations on the bird. When they have finished the physical prototype they also return to the design brief to check they have covered most of it. Throughout the process they become increasingly specific on how their ideas for interaction such as wing flapping could be designed to express different things, and also how they need to constrain the different actions that could be performed.

\section{Explorative interactions between designers and materials}

In the first excerpt the students move from talking about the physical properties of the bird to explore how those could be used to perform interactions through the bird. Here they discuss the topic of how to send messages through the bird.

\section{Excerpt 1}

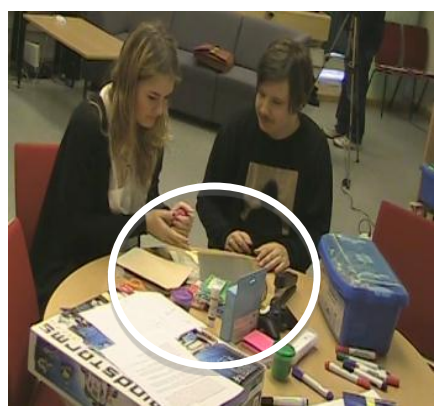

Figure 1. Molding the clay

Anna: Maybe we should think like this ... how do you do to send a message to other people? 


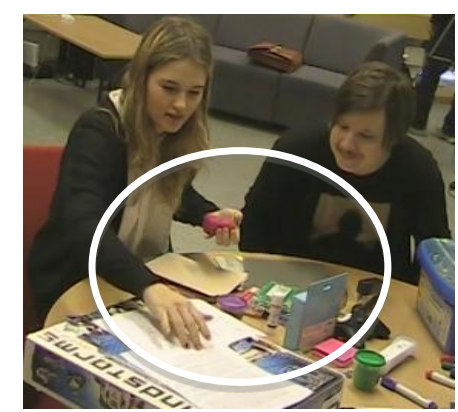

Figure 2. Checking the brief

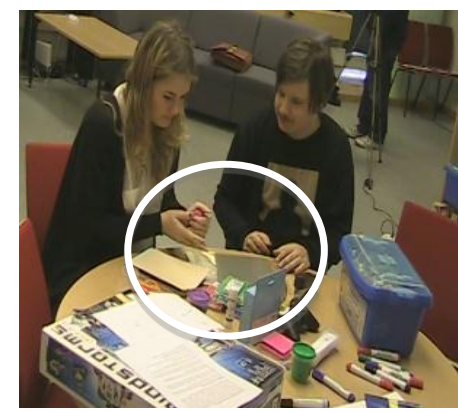

Figure 3. Both looking at clay in Anna's hands

Anton: Hmm...from a bird you mean?

Anna: Ah

Anton: Hmm...

Anna: ...and how do I choose it?

Anton: Mmm, for example who I am sending to?

Anna: Ah

Anton: Really, I cannot see how that should work without the screen. One can imagine that...you have certain movements on it that represents different people

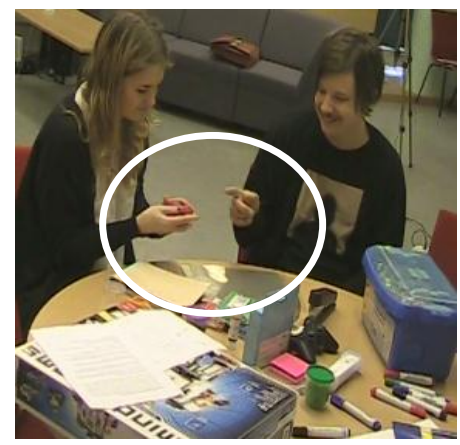

Figure 4. Anton points at clay bird

Anna: Let's add wings as well

The requirements in the brief state that they should design something without a screen. The mouldable piece of clay, and their idea of a physical bird, leads to the suggestion that "certain movements can represent certain people". At this point, they are working on moulding the body of the bird in purple clay. Just prior to this they have discussed how they can interact with the bird without relying on any kind of screen interaction. This problem is here reformulated rather broadly in the first two lines, first that they need to consider how messages should be sent, and second that this could be achieved by manipulating the bird itself. Obviously, from the conceptual idea of a real bird, there is no direct transformation of this into an interactive artefact. The lack of a screen leads them to explore how the properties of a bird can help them imagine different ways of interacting.

Throughout Excerpt 1 there are two material objects in play, the clay and the design brief. These are continuously attended to by the participants and reshape the unfolding design idea. The material objects play an important role in the process of shaping the prototype and the participants are responsive to the two different materials. The sequence ends with the suggestion to add wings to the bird, as a potential interactive property. This suggestion builds on the participants' simultaneous interactions with the clay, pieces of paper, their reading and interpretation of the brief. As illustrated in Excerpt 1, the brief is carefully considered as a source defining the task. As a material object, the brief comes into play when attended to by the participants and, in that interaction, it performs the work of defining and reflecting the boundaries of the task, thus facilitating the progression. The clay and pieces of paper provide creative possibilities to manifest and make the design decision temporally set for this particular point in the design process. While the participants give shape to the material, the material is not only a representation of their idea but it also contributes with new inspirational possibilities for the participants to perform around.

The material resources contribute in producing the creative actions that the students pick up and respond to through their design suggestion. The design brief provides a framework of information on how the artefacts should work, while the clay provides a mouldable material that can be purposefully shaped to express design ideas. The brief thus frames the problem/idea, while the clay allows for a specific embodiment of their idea at this particular moment.

The instantiation in clay works as partial sketch and it does not represent the whole idea at this stage. It is through the particular arrangement of these materials that the idea temporally emerges and gets produced. The materials are thus not static objects that the students can explore to find certain possibilities in, rather they actively contribute to the design process through the way they are arranged, their relation to one another, and to the participants.

\section{Flapping wings}

As the design process continues, the participants clarify the various actions that the material object may perform. 


\section{Excerpt 2}

Anna: Do you think one should be able to lift the wings

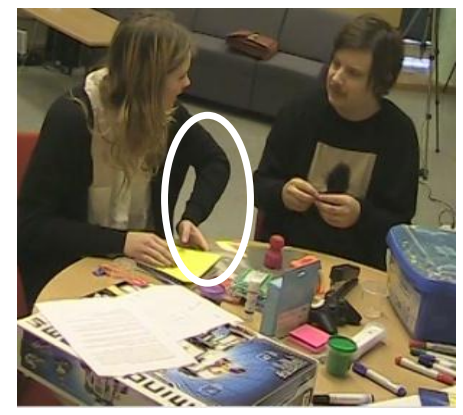

Figure 5. Anna lifts her left arm like a wing flap

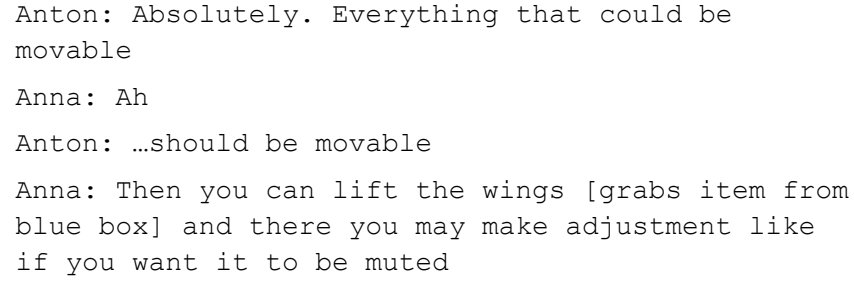

Anna and Anton have started to think of the different body parts that are included in the bird prototype (beak, wings, feet, eyes). While Anna holds the clay bird in her hand, she initializes a discussion regarding what interactive properties that could be performed through moving the wings of the bird. Anton responds to this by claiming that it is fun if things could move and be moved. A prototypical concept of a bird has wings to fly with, which Anna and Anton use as an idea for interaction. However, the suggestion that the interactions for accessing different settings could be hidden under a wing does not make specific use of the wings as an interaction mechanism, rather it uses the physical properties of the bird to "attach" interactions to it, such as a mute button. Even though this is a quite simple suggestion for interaction through the bird, it is illustrative of how properties from the concept of a bird contribute to shape the design ideas.

This sequence results in the proposal to use wings as an interactive element of the prototype. The added wings and Anna and Anton's prototypical idea of a bird forms the basis for specifying the interaction modalities (see Figure 5). To explore this, Anna lifts her arm in the shape of a wing, thereby enacting the flapping of wings through a gesture which is overlaid onto the design object. This reflects how the human performances are starting points for specifying interactive property that further on could be ascribed to the design object.

The materials are not static objects that the participants can discover qualities in, but rather performative objects that actively contribute to the design process. In Excerpt 2, the material objects bring forth ideas that things should be movable, that it should be possible to lift the wings, and that interactive properties could be placed underneath them. The lump-shaped piece of clay is a partly manifest idea in the shape of a bird onto which wings are being attached, Thereby, the particular material configuration, together with the metaphor of a bird, give shape to the design idea.

\section{Blending materials}

Excerpt 3 further details how the different materials perform in the design process

\section{Excerpt 3}

Anna: It could be a yellow beak in this

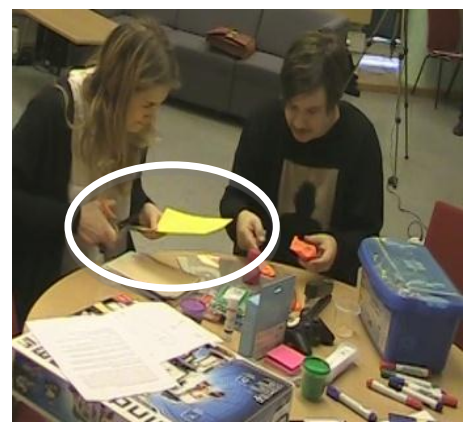

Figure 6. Anna starts cutting yellow paper

Anna: ahem

Anton: but this was the beak

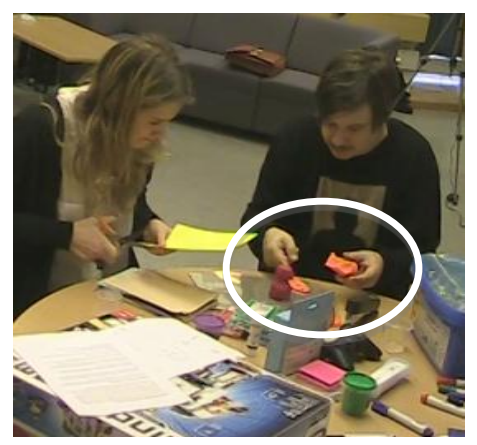

Figure 7. Anton moulds a beak in orange clay, points at bird body

Anna: yeah right

Anton: Great beak format

Anna: Should we have wings in that

Anton: D'you think that it should be possible to lift the wings?

This excerpt involves several choices of materials other than clay used for the body of the bird. First, they use orange clay for the beak and then regular white paper to cut out the wings from. This makes the different parts of the bird visually distinguishable from one another. However, various materials allow for various kinds of interactions. Regular paper is light, flexible and easy to fold. When shaped into a thin wing and attached to the clay body of the bird, it enables a set of actions that could be conducted with the wing such as folding, lifting, or flapping it. In contrast, the beak in orange clay is distinguishable from the rest of the body of the bird because of its colour and shape, but not 
through other contrasting material qualities. It thereby allows fewer manipulations that could be performed on it. By using different materials for different body parts and attaching them to the body of the bird, different opportunities for creative exploration of interaction qualities are opened up. The transformation and blending of the material through several stages embody properties of their idea of a physical twittering technology. If we look at Excerpt 3, as well as the earlier ones, the idea emerges through the clay bird, is enacted in the physical performances of the participants, and their interpretation of the design brief.

\section{Materializing an idea}

In Excerpt 4, Anna and Anton extend the physical properties of the bird by attaching coloured Lego pieces as eyes and legs.

\section{Excerpt 4}

Anton: Looks like a real ghost bird

Anton: But note the red and the green one here

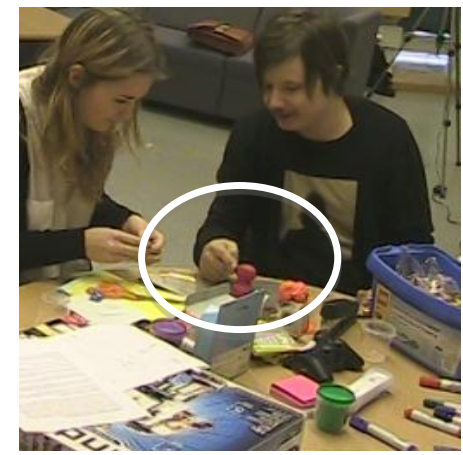

Figure 8. Anton points at the eyes of the bird
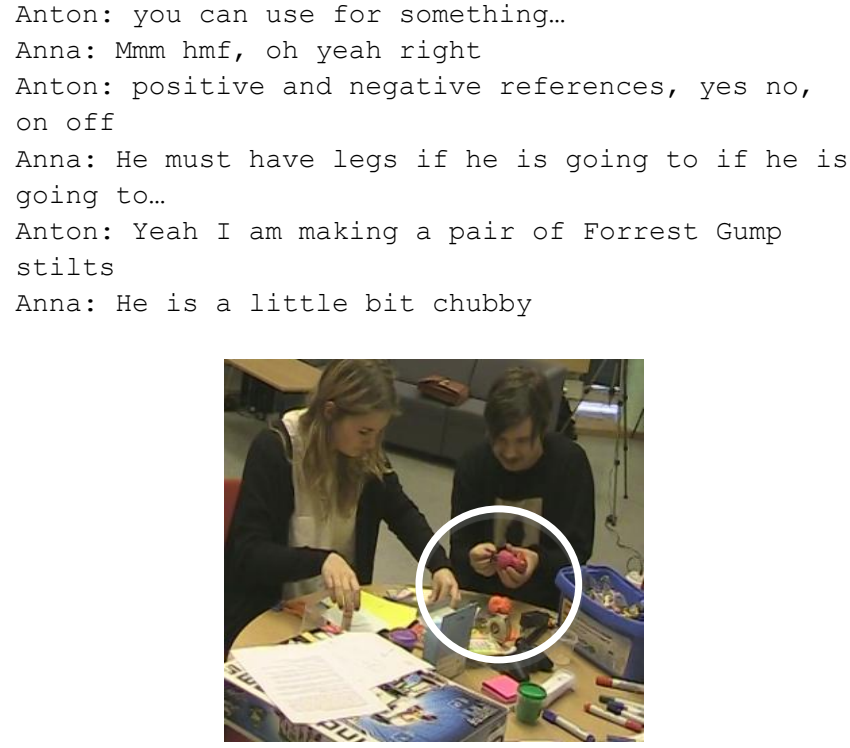

Figure 9. Anton attaches Lego pieces as legs

Initially, the eyes are attached mostly for decorative purposes without any interactive properties. However,
Anton's idea "you can use it for something", suggests that these could play a role in the interaction, such as representing different feelings (negative or positive) or other expressions that users would want to make in the interaction. They do not further develop this line of reasoning, but move on to design the physical prototype. The next proposal, that "he [the bird] must have legs" is probably formulated with a reference to what was said in Excerpt 2, "that everything that could be movable should be movable".

The practical outcome of this section is the completion of the bird prototype, while there is a simultaneous development of the interactive properties of their idea. As these takes place, a new layer of perceiving the object comes in to the picture, the bird performs a number of characteristics visible in the talk above; like being ghostlike and chubby. The bird is referred to as a "he", with its own an identity and personality. In summary, the continuous additions of physical properties in various materials actively shape the on-going design and here provide a specific direction and possibilities for generating new ideas.

\section{TOWARDS A MATERIAL AGENCY IN HCI}

Through our analysis of the material aspects of interaction design discourse we have aimed to contribute to an understanding of how materiality constrains and enables what can be expressed and designed, and thereby provides a starting point for a conceptualisation of agency in interaction design. Actions of people and material together contribute to the "doing" and the forming of a designed object. It is through the unfolding of such transactions that agency emerges. Agency is thus not a property of each individual actor, neither is it a pre-given property of an artefact. The agency of a design material does not merely depend on its physical qualities, but is an emergent relationship. In comparison to metals, which cannot only be characterized by different degrees of conductivity and ductility, the different properties of various design materials reflect the way they are actually used within design processes.

In our analysis, we have illustrated how such qualities emerge, while regarding them as emergent issues of agency rather than affordances. The difference, we argue, is not merely linguistic, but concerns the way we consider the role of materials in interaction design. For instance, if the affordance of clay suggests to designers that it can be moulded, the notion of agency enables us to consider the way that the clay continuously shapes and reconfigures the on-going dialogue between materials and designers. It is in this process of doing and performing that the design object emerges, in the case considered, in the shape of a bird. The notion of agency allows for reflection on the creative intraactions whereby a lump of clay has played a part in the design of the concept of a twittering bird. 
In the following sections, we discuss a set of concerns that emerged from our analysis:

- Bodily and material configurations.

- Material limitations and opportunities.

- Talking about material interactions.

\section{Bodily and material configurations}

Initially, the design process revolved around the textual description in the design brief, sketching out a preliminary interpretation that could be developed into a design object. This was done through quick drawings on paper, overlaid by the participant's talk and bodily actions. Bodily movements in relation to the paper sketches served as a way of exploring possible movements that could be used in the interactions by and with the physical twittering bird. This way of linking and overlaying the textual object (design brief) with movements and gestures continuously occurred throughout the design process. In line with a number of other studies, this shows how it is actually quite difficult for a designer to explicate the way materials talk back, but requires in-situ improvisation to express design ideas [30]. Furthermore, it illustrates how bodily movements are an actual way of creating a physical, interactive design object.

\section{Material limitations and opportunities}

When the participants translate their design idea into a physical prototype/sketch through the physical resources at hand, there are a number of assumptions made. These are arguably established by relating to the idea of real birds and their possible body movements, which is in turn related to the material resources, such as clay and paper, and their possibilities and constraints. One such assumption comes out of the size of the clay bird. The amounts of clay available for the design most likely affect the kind of interaction envisioned. The size emerges from the available material as well as preconceptions about devices for how interaction of this kind should practically work. It is also implicitly assumed, and not explicitly negotiated, that the twitter bird is to be interacted with hands and fingers. It should be touched and held in a pet-like fashion, thus resembling the behaviour of other familiar objects such as mobile devices, game controllers, children's toys, and Tamagotchis.

\section{Talking about material interactions}

When analysing our data it was noticeable that the students as well as we as analysts lack a conceptual language in order to talk about the interactive qualities of the available design material. To illustrate some aspects of what this shortage consists of let us reflect on some central aspects of our empirical data.

It is notable that a significant portion of the participants' communication about interactive qualities was achieved through body movements and actions rather than through talk. In Excerpt 3, there is a comment about the beak: "great beak format" but it is never put into words in what sense the choice of orange clay is suitable for the beak. Similarly, in Excerpt 1, one of the participants expresses worries that the interaction will be difficult without a screen ("Really, I cannot see how that should work without the screen."), but as the "flappable" paper wings are physically added, alternative solutions for interaction modalities emerges. On a general level, this suggests that the interactive qualities emerges through material interactions, and implicitly that there is a limitation to the conceptual language available for discussing interactive qualities in materials. The clay material can be handled in different ways, it can be cut, moulded, stretched, pecked, and so on, but the way the material responds to these actions is harder to describe in terms of design. We argue that this issue needs further exploration: i.e. ways of talking about how interactive design materials contribute to the unfolding reconfigurations of a design idea.

Understanding design practices regards how people and material objects develop design objects in interplay. Our argument is that the material itself enacts certain aspects of the design activity as it unfolds. Material objects should thus not only be understood as objects that give and get meaning through human representational activity only. Hence, it is not only the actions of humans that inscribe meaning into the design objects, but the objects become meaningful through specific material configurations.

In summary, we have shown how design concepts emerge on a multitude of levels: (i) through delegation of roles such as for facilitation, inspiration, and metaphor for concrete design actions. (ii) from separate material objects to a shaped design object (iii) from a basic idea to well-defined interactive artefact (iv) from physical performance to embodied object.

\section{REFLECTIONS ON THE CONCEPTION OF AGENCY}

Earlier conceptions of agency often equated it with intentionality and the kind of intelligible, 'smart' behaviour sometimes reserved for humans. Such a notion of agency easily leads into 'deep and murky waters' requiring answers to the fundamental questions regarding the nature of human intelligence and the basic requirements for building machine intelligence. Distributed cognition [10] and embodied interaction [5] among others, have made important contributions in reorienting away from cognitive conceptions and essentialist claims regarding the nature of intelligence. Instead, they proposed ways of reconceptualising these problems by addressing intelligence as a phenomenon that is constantly subject to change and is 'produced' through our everyday actions [26], [28]. In a similar vein, STS researchers such as Barad [1] and Pickering [21] suggest a rethinking of agency, as something that emerges and is dynamically enacted through practice, rather than as a property of a particular actor. According to Barad and Pickering, this is in line with a way of thinking that attempts to make room for a richer understanding of materials in social constructivist theory, and what is claimed to be an often overly strong focus on language in human meaning making [1], [21]. Instead, humans and material objects intra-act; i.e. not only do the humans 
construct meaning out of their representational acts, but the objects themselves actively contribute in the meaning making process. To capture such processes, Barad proposes the notion of phenomena to be the primary ontological units, rather than humans and things. She opposes the view that humans and things are units with inherent boundaries. Instead, she suggests a focus on phenomena as larger assemblies of intra-acting components of humans and things [1].

We propose that we look upon design processes as the phenomenon of "design-activity-together-with-designobjects". The notion of intra-action is critical to this. It shows how a design process is an on-going performance, rather than relations between independent agents (human and thing). Agency is thus not an attribute of things but, an "on-going reconfiguring of the world" [1]. Dynamics and change is thus created through agency. Taking this perspective, the design of the physical twittering device was orchestrated by the participants' own actions, as well as by the material resources. Our concern was thus not with the particular qualities of the participants' experience, but rather how the crafting of the designed concept was enacted by humans as well as material objects. This gives materiality in interaction design a central role and provides a conceptualisation for purposefully exploring the qualities of different material objects.

\section{CONCLUSIONS}

Recent developments in interactive objects and materials rapidly increase the amount of digital artefacts in our everyday lives. This makes the boundaries between digital and non-digital realms to be increasingly blurred. A consequence of this is that what constitutes an interactive object has to be seen as constantly shifting dependent on context and activity. What users experience as the properties of particular materials continuously shift, and thus need to be understood in emergent and relational terms.

Agency is reflected in how performances of humans and material objects enact qualities that get ascribed to the object under design. Thereby agency temporally emerges in practice, meaning that it is never decidedly known in advance but rather shifts depending on the particular configurations of actors and objects. This perspective on how to understand the role of material objects in design and interaction, suggest that we need to look for agency as it unfolds in a particular situation. Materials can thus not be understood as having different states that change through human action, but are also performing agents, and consequently changes the situation.

The starting point of this work was to further explore processes of how design materials 'talk back' in interaction design. Through the notion of agency we have investigated the relationships and actions of people and material objects in the production of a design object. In so doing, we have particularly focused on analysing material interactions in a design process. We have argued that materials play a role in design processes that goes further than generally conceived in HCI, by looking at them not only as representational objects but as actants. By scrutinizing the material as it is transformed throughout the design, we have been able to identify a set of themes that we argue helps to draw attention to the interdependency of people and material in design. We started out our analysis by loosely connecting to Latour's notion of agency [14], from which agency is a phenomenon that emerges through a process of delegation of roles in a particular context, which allows material objects to take on the performance of certain tasks, that otherwise would be performed by people.

We argue that there are several benefits from revisiting interaction design processes from the assumption that agency is distributed in the continuous reconfiguration of people and artefacts within a phenomenon. When studying the design process, the notion of agency helped us understand how materials contribute and become actors, rather than mere objects to be acted upon. In so doing, we hope to have illustrated how materials 'talk back' to designers, as put by Schön. Several issues emerged in our study, first, that our vocabularies and conceptualizations for discussing material interactions are limited. By looking at a concrete design situation we have illustrated a perspective for understanding such interactions in relation to the material in the design process. For interaction design, this is particularly relevant through its concern with how material interactive objects are shaped, as well as to reflect on the nature of this practice and how it is to be fruitfully conducted.

\section{REFERENCES}

1. Barad, K. Posthumanist Performativity: Toward an Understanding of How Matter Comes to Matter. In: Signs: Journal of Women in Culture and Society. 28(3). (2003).

2. Bardzell, J \& Bardzell, S. Interaction criticism: a proposal and framework for a new discipline of HCI. Proc. CHI 2008. ACM Press. (2008).

3. Binder, T., De Michelis, G., T., Ehn, P., Jacucci, G., Linde, P., Wagner, I. Design Things. Cambridge, MA : MIT Press. (2011).

4. Coyne, R. D., \& Snodgrass, A. D. (1991). Is designing mysterious? Challenging the dual knowledge thesis. Design Studies, 12(12, 3), 124-131.

5. Dourish. P. Where the action is. Foundations of Embodied Interaction. MIT Press. 2001.

6. Dourish, P. Seeing Like an Interface, Proc $\mathrm{OzCHI}$. ACM Press. (2007).

7. Fallman., D. Design-oriented human-computer interaction. Proc. CHI '03. ACM Press, New York, NY, USA, (2003). 225-232.

8. Gibson, J. The Theory of Affordances. In Perceiving, Acting, and Knowing, Eds. Shaw, R., and Bransford, J. (1977). 
9. Hayles, K. How We Became Posthuman:Virtual Bodies in Cybernetics, Literature and Informatics. Chicago: University of Chicago Press. (1999).

10. Hutchins. E. Cognition in the Wild. MIT Press. (1995).

11. 11. Iacucci, G., Wagner, I. Supporting Collaboration Ubiquitously: An augmented learning environment for architecture students. Proc ECSCW'03. Kluwer Academic Publishers, (2003). pp. 139-158

12. Jacucci, G., Wagner, I., Performative Roles of Materiality for Collective Creativity. Proc Creativity and Cognition 2007, (2007), ACM Press.

13. Laaksolaahti., J. (in preparation). Broken but polished. Unpublished Manuscript.

14. Latour B. On Interobjectivity. In Mind, Culture and Activity, Vol 3 (4) (1996). 228-245.

15. Lave, J. Cognition in Practice. (1988). Cambridge University Press.

16. Löwgren, J. and Stolterman, E. Thoughtful Interaction Design: A Design Perspective on Information Technology. The MIT Press. (2004).

17. Jordan B., Henderson A.. Interaction Analysis: Foundation and Practices. The Journal of the Learning Sciences, 4 (1). (1995). 39-103.

18. Martin, D, O'Neill, J and Randall, D. Talking about (my) Generation': Creativity, Practice, Technology \& Talk. Proc ECSCW. (2009). pp. 171-190.

19. Murphy, K. M.. Collaborative imagining: The interactive use of gestures, talk, and graphic representation in architectural practice. Semiotica, 156(1/4), (2005) 113-145.

20. Norman, D. The Design of Everyday Things, Doubleday Business Press. (1990).

21. Pickering, A. The mangle of practice. University Of Chicago Press, (1995).

22. Robles, E. \& M. Wiberg. Texturing the 'Material Turn' in Interaction Design, Proc TEI 2010. ACM Press. (2010).
23. Rosner, D. and Taylor, A. S. Antiquarian answers: book restoration as a resource for design. Proc CHI '11. ACM Press, (2011). 2665-2668.

24. Schön, D. The Reflective Practitioner. How Professionals Think In Action. Basic Books. (1983)

25. Suchman, L. Plans and Situated Actions: the problem of human-machine communication. New York: Cambridge University Press. (1987).

26. Suchman, L.. Human-Machine Reconfigurations: Plans and Situated Actions. (2006). Cambridge University Press

27. Sundström, P \& Höök, K. Hand in hand with the material: designing for suppleness, Proc CHI 2010, ACM Press. (2010).

28. Taylor, A. S. Machine intelligence. Proc CHI '09, ACM Press (2009). pp. 2109-2118.

29. Tholander, J., Karlgren, K., Ramberg, R., and Sökjer, $P$. Where all the interaction is: sketching in interaction design as an embodied practice. Proc DIS '08. ACM Press, (2008), 445-454.

30. Vallgårda, A \& Redström, J. Computational Composites. Proc CHI 2007. ACM Press. (2007). pp. 513-522

31. Wiberg, M, and Robles, E.. Texturing the "material turn" in interaction design. Proc TEI 2010. ACM Press. (2010)

32. Wright, P \& J. McCarthy. Experience-Centered Design., Morgan \& Claypool Publishers. (2010).

33. Wolf, V.T., Rode, J., Sussman, J., and Kellogg, W. Dispelling "design" as the black art of CHI. Proc CHI '06. ACM Press, (2006). 521-530.

34. Zimmerman, J., Forlizzi, J., and Evenson, S.. Research through design as a method for interaction design research in HCI. Proc CHI '07. (2007). 493-50. 